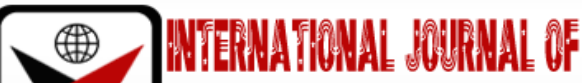

\section{Molecular Identification and Antimicrobial Sensitivity Profile of Bacteria Isolated from Food Handlers in Akure Nigeria}

\author{
Onifade, A. Kayode \\ Lecturer, Department of Microbiology, Federal University of Technology Akure, Nigeria \\ Mustapha, K. Azeez \\ Lecturer, Department of Science Laboratory Technology, Rufus Giwa Polytechnic, Nigeria
}

\begin{abstract}
:
Hand washing and hand swab samples culminating to a total of 477 samples were collected from different food vending locations in Akure. Bacteria were isolated and identified, after which the sensitivity patterns of the isolates to standard antibiotics and plant extracts were determined using disc diffusion agar and well diffusion methods, respectively. The bacterial isolates include Escherichia coli, Klebsiella oxytoca, Klebsiella pneumoniae, Micrococcus luteus, Proteus mirabilis, Proteusvulgaris, Pseudomonas aeruginosa, Salmonella enteritica, Salmonella typhi, Serratia marcescens, Shigella sonnei, Staphylococcus epidermidis, Staphylococcus aureus and, Streptococcus pyogenes. Staphylococcus aureus was observed to be the most prominent bacteria harboured by the food handlers. The isolated bacteria were subjected to $16 \mathrm{~s} r$ RNA polymerase chain reaction, DNA gene extraction and sequence blasting using the amplified length of 1500 base pair. The sequence obtained was blasted in National Centre for Biotechnology Information (NCBI) database. Based on the 16s rRNA sequences, the following bacteria were confirmed; Escherichia coli str. K12 substr. DH10B, Klebsiella pneumoniae strain J1, Proteus mirabilis strain HI4320, Pseudomonas fluorescens SBW25, Salmonella enterica subsp.enterica serovar Typhi str. CT18, Salmonella enterica subsp. enterica serovar Infantis, Shigella flexneri $2 a$ str. 2457T and Staphylococcus cohnii subsp. cohnii strain 532 Contig16. Phylogeny was employed in the phylogenetic tree construction due to its robustness, reliability and less-laboriousness. The result of the sequence was aligned and the phylogenetic tree constructed shows the evolutionary relationship between eight bacterial species. Two clusters were generated; Salmonella enterica subsp. enterica serovar Typhi, Salmoenella typhi LN854584.1 Staphylococcus cohnii, and Staphylococcus aureus are in cluster 1, Proteusmirabilis NC0100554.1, Bacillus thuringiensis KY652120.1 and Bacillus subtilis MG231261.1 is incluster 2. However, bacteria in the same cluster were observed to have different phenotypic characteristics. The antibacterial efficacy of the selected medicinal plant extracts (Ocimum gratissimum and Annona muricata) were copared to that of standard antibiotics (Ciprofloxacin, Nitrofurantoin, Ampliclox, and Chloramphenicol) using three different solvents (methanol, water and petroleum ether) at $50 \mathrm{mg} / \mathrm{ml}, 100 \mathrm{mg} / \mathrm{ml}, 200 \mathrm{mg} / \mathrm{ml}$ and $300 \mathrm{mg} / \mathrm{ml}$, concentrations. Bioactive characterization of the selected plants revealed the presence ofvarious active components such as Thymol, Eugenol, Caryophyllene, Gamma-terpinene, 8-methyl-4-vanillyl-7-nonenamide, N-4-Hydroxy-3-methoxybenyl 8methyldec 6 enamide, DL-6, 8tio acidamide and N-4-Hydroxy-3-methoxyphenyl methyl nonanamide. Phytochemical analysis of the plants affirmed the presence of Tannins, Alkaloids, Flavonoids, Anthraquinone and Saponins in O. gratissimum and A. muricata. It can be deduced from this study that food handlers play a major role in the transfer of bacterial contaminants to the edible food. Also, the metabolites present in 0 . gratissimum and A. muricata render these plants cost effective alternative source of therapy to food borne illnesses.
\end{abstract}

Keywords: Antimicrobial sensitivity, molecular identification, ocimum gratissimum, annona muricata, food handlers, antibiotics

\section{Introduction}

Food handler refers to any person involved in food processing from its raw form to the edible form. The human skin surface harbours large numbers of bacteria that can be readily dislodged and transferred to surfaces upon touching, hence the importance of proper hand hygiene by health care practitioners and food handlers (Jarvis, 2017). When an individual swallows bacteria that cause food poisoning, there is a delay (incubation period) before symptoms begin. This is because most bacteria that cause food poisoning need time to multiply in the intestine. The length of the incubation period depends on the type of bacteria and how many are swallowed. It could be hours or days. The bacteria stick to the lining of the intestine and destroy those cells, either by sheer weight of numbers or by the toxins (poisons) they produce (Liu, 2017). Sometimes these toxins are absorbed and cause damage elsewhere in the body. Some bacteria produce toxins when they grow in food. Because the toxins themselves are harmful, the bacteria don't need to multiply in the intestine to make someone ill, so the symptoms come on very quickly (Weisblum and Davies, 2015). Since the bacteria enter the body 
through the digestive system, symptoms will generally be in the form of nausea, vomiting, abdominal cramps and diarrhoea. In some cases, food poisoning can cause very serious illness or even death (Liu, 2017).

Traditional methods of bacterial identification rely on phenotypic identification of the causative organism using gram staining, culture and biochemical methods. However, these methods of bacterial identification suffer from two major drawbacks.

First, they can be used only for organisms that can be cultivated in vitro. Secondly, some of the strains exhibit unique biochemical characteristicsthat do not fit into patterns that have been used as a characteristic of any known genus and species (Ashelford et al., 2015).Developed in 1983 by Kary Mullis, PCR is now a common and often indispensable technique used in clinical laboratories and research laboratories for a variety of applications. In the past decade or so, molecular techniques have proven beneficial in overcoming some limitations of traditional phenotypic procedures for the detection and characterization of bacterial phenotypes.

\section{Materials and Methods}

\subsection{Collection of Samples}

A total of four hundred and seventy-seven (477) samples were collected between the hours of 8am-9am within October and December 2017 using sterile swab sticks already moistened with normal saline at the cotton tips so as to ensure easy adherence of microbes to it. The sticks were used to swab the palms of food handlers in various locations within Akure metropolis. Hand washing technique was also employed in collection of the samples. Distilled water was used to rinse the hands of food handlers into sterile containers. All the samples collected were placed in an ice bag.

\subsection{Sterilization of Materials Used}

All the glassware (Petri dishes, beakers, conical flasks) used were washed thoroughly with detergent, rinsed with tap water and then oven dried at $160^{\circ} \mathrm{C}-170^{\circ} \mathrm{C}$ for 2 hours. Forceps and inoculating loops were flamed to red-hot and then dipped in $70 \%$ ethanol. Laboratory benches and inoculating chambers were thoroughly disinfected with cotton wool previously soaked in $70 \%$ ethanol before and after investigations.

\subsection{Culture Media Preparation}

Growth media used for this study were prepared according to manufacturer's specifications. Dehydrated Nutrient agar (2.8g), EMB (3.8g), MacConkey agar (5g), Salmonella Shigella agar (6g), Mannitol salt agar (11.1g), Simmon citrate agar (2.4g) and Muellar Hinton agar (3.8g) were separately dissolved in $100 \mathrm{ml}$ of distilled water, in a $250 \mathrm{ml}$ capacity conical flask. Complete dissolution was achieved by placing on hot plate at $50^{\circ} \mathrm{C}$ for 45 mins. Thereafter, the flask was corked with cotton plug and then wrapped with Aluminium foil. The medium was later sterilized in an autoclave at $121^{\circ} \mathrm{C}$ for 15 mins.

\subsection{Isolation and Identification of Bacterial Isolates}

Samples were transported to the laboratory and analyzed within 1 hour of collection. Serial dilution of the swab sticks and the water samples was employed in transferring the bacteria to the agar plates so as to reduce the microbial population. Samples were inoculated onto nutrient, chocolate, blood, and MacConkey plates. All plates were incubated aerobically at $37^{\circ} \mathrm{C}$ for 24 to $48 \mathrm{hr}$ except the chocolate agar plates that were incubated in a candle jar. Emergent bacterial colonies were identified by standard bacteriological techniques (Cheesbrough, 2010). The pure isolates were stored on slants and kept at $4^{\circ} \mathrm{C}$ for further use (Fawole and Oso, 2007).

\subsection{Cultural Identification}

Cultural characteristics of the distinguished bacteria colonies such as colour, shape, pigmentation and opacity were observed and noted after 24 hours of incubation. Microscopic characterization was done using Gram staining procedure, biochemical tests were done according to the methods of Olutiola et al. (2011); Fawole and Oso (2007); Cheesbrough (2010) and identification of bacterial isolates was carried out using the method of Cowan and Steel (2016).

\subsection{Biochemical Characterization of Bacterial Isolates}

The standard methods of Fawole and Oso (2007) and Cheesebrough (2010) were used for the biochemical characterization of bacterial isolates.

\subsection{Molecular Identification of Bacterial Isolates}

This test was carried out according to the method of Heikens et al. (2015).

\subsection{Antibiotic Sensitivity Test}

The antibiotic sensitivity test was carried out according to Asoso et al., (2016).

\subsection{Preparation of Plant Extracts}

The leaves of the Ocimum gratissimum (efinrin) and Annona muricata (sour sop) plants was harvested and identified at the Crop, Soil and Pest Management Department (CSP) Department of the Federal University of Technology, Akure. Then they were properly rinsed with tap water, air-dried at room temperature and then pulverized to powdered form. A 400g portion each of the powdered sample was soaked separately for $72 \mathrm{hr}$ in three solvents namely: $70 \%$ 
methanol, distilled water and petroleum ether. Each solution was first sieved using muslin cloth and then filtered with No 1 Whatman (Asoso et al., 2016). The filtrate was evaporated in a rotary evaporator (Buchi Rotavapor R-200 Heidolph, Vassembly, manufactured by Lyman C. Craig) to concentrate the crude extracts. The $100 \%$ stock concentration of the extracts was obtained and stored at $4^{\circ} \mathrm{C}$ in a corked universal bottle. It was reconstituted with $30 \%$ Tween-20 to obtain 50 $\mathrm{mg} / \mathrm{ml}, 100 \mathrm{mg} / \mathrm{ml}, 200 \mathrm{mg} / \mathrm{ml}$ and $300 \mathrm{mg} / \mathrm{ml}$ of each of the plant extracts. Prior to sensitivity test, the various concentrations of the extracts were filtered using a millipore membrane filter of $0.45 \mu \mathrm{m}$ pore size to ensure the sterility of the crude extracts.

\subsection{Phytochemical Screening}

The phytochemical analysis was carried out according to the standard methods of analysis by analytical methods Committee of Royal Society of Chemistry, (2002).

\subsection{Data Analysis}

The experiment was carried out in triplicates and the data obtained was subjected to statistical analysis using SPSS version 22, Treatment means were compared using Duncan's New Multiple Range test and significant differences were evaluated at $p \leq 0.05$.

\section{Results and Discussions}

All the bacterial isolates showed different biochemical reactions and were characterized morphologically based on microscopy into cocci and bacilli. The isolates were identified as Alcaligenes faecalis, Bacillus cereus, Bacillus subtilis, Citrobacter freundii, Enterobacter aerogenes, Escherichia coli, Klebsiella oxytoca, K. pneumoniae, Micrococcus luteus, Proteus mirabilis, P. vulgaris, Pseudomonas aeruginosa, Salmonella typhi,Serratia marcescens, Shigella sonnei, Staphylococcus aureus, $S$. epidermidis, and, Streptococcus pyogenes. After the presumptive identification, $S$ aureus was observed to be the most prominent having eighty-five (85) isolates while Serratia marcescens, Shigella sonnei, recorded the least number of isolates two (2) isolates.

The length of amplified products was 1500 base pair. The sequence obtained was blasted in National Centre for Biotechnology Information (NCBI) database. Based on the 16s rRNA sequences, the following bacterium were confirmed; Escherichia coli str. K12 substr. DH10B, Klebsiella pneumoniae strain J1, Proteus mirabilis strain HI4320, Pseudomonas fluorescens SBW25, Salmonella enterica subsp.enterica serovar Typhi str. CT18, Salmonella enterica subsp. enterica serovar Infantis, Shigella flexneri 2a str. 2457T and Staphylococcus cohnii subsp. cohnii strain 532 Contig16. The result also revealed a difference in cultural identification of Staphylococcus cohnii subsp. cohnii strain 532 Contig16, Salmonella enterica subsp. enterica serovar Infantis and Pseudomonas fluorescens SBW25.

The antibiotic sensitivity profile of bacteria isolated from food handlers in Akure metropolis is shown in Table 1.0. Ciprofloxacin was the most potent antibiotic agent on the isolates. The zone of inhibition ranged from $9.25 \pm 0.31$ to $11.57 \pm 0.30 \mathrm{~mm}$. This antibacterial agent exerted its highest effect on Staphylococcus aureus while the least effect was on Enterobacter aerogenes. Staphylococcus aureus was also observed to be the most susceptible bacterium to Nitrofurantoin with an inhibitory zone of $10.46 \pm 0.23 \mathrm{~mm}$ while Proteus mirabilis was the least susceptible with a zone of $8.60 \pm 0.27 \mathrm{~mm}$. Ampiclox demonstrated its highest antimicrobial effect on Streptococcus pyogenes (10.46 $\pm 0.26 \mathrm{~mm}$ ), while Bacillus thuringiensis was least susceptible to Ampiclox with an inhibitory zone of $8.26 \pm 0.26 \mathrm{~mm}$. Chloramphenicol appeared to be the antibacterial agent with the least efficacy, the zone of inhibition ranged from $7.52 \pm 0.28 \mathrm{~mm}$ (Serattia marcescens) to $9.57 \pm 0.28 \mathrm{~mm}(S$. aureus).

Tables 2 to 7 represent the antibiotic sensitivity patterns of the bacterial isolates to methanol, water and petroleum ether extracts of 0. gratissimum and $A$. muricata at the concentrations of $50 \mathrm{mg} / \mathrm{ml}, 100 \mathrm{mg} / \mathrm{ml}, 200 \mathrm{mg} / \mathrm{ml} \mathrm{and}$ $300 \mathrm{mg} / \mathrm{ml}$. The zone of inhibition of methanolic extract of 0 . gratissimum extracts ranged from $5.32 \pm 0.37 \mathrm{~mm}$ to $20.56 \pm 0.70 \mathrm{~mm}$. Its water extracts recorded inhibitory range $3.67 \pm 0.10 \mathrm{~mm}$ to $18.42 \pm 0.28 \mathrm{~mm}$. Petroleum ether extracts demonstrated the least efficacy with inhibition zones ranging from $1.80 \pm 0.34 \mathrm{~mm}$ to $9.13 \pm 0.35 \mathrm{~mm}$. On the other hand, water extracts of $A$. muricata was the least effective with zones of inhibition ranging from $3.02 \pm 0.10 \mathrm{~mm}$ to $12.99 \pm 0.98$ $\mathrm{mm}$.

\begin{tabular}{|l|l|l|l|l|}
\hline & \multicolumn{1}{|c|}{ A } & \multicolumn{1}{c|}{ B } & \multicolumn{1}{c|}{ C } & \multicolumn{1}{c|}{ D } \\
\hline Escherichia coli & $9.42 \pm 0.04^{\mathrm{c}}$ & $8.50 \pm 0.03^{\mathrm{b}}$ & $8.43 \pm 0.32^{\mathrm{b}}$ & $9.91 \pm 0.38^{\mathrm{d}}$ \\
\hline Klebsiella oxytoca & $9.50 \pm 0.01^{\mathrm{d}}$ & $8.70 \pm 0.04^{\mathrm{c}}$ & $8.43 \pm 0.04^{\mathrm{b}}$ & $10.04 \pm 0.01^{\mathrm{e}}$ \\
\hline Klebsiella pneumonia & $10.37 \pm 0.20^{\mathrm{d}}$ & $9.30 \pm 0.52^{\mathrm{c}}$ & $8.53 \pm 0.27^{\mathrm{b}}$ & $10.47 \pm 0.24^{\mathrm{d}}$ \\
\hline Proteus vulgaris & $8.53 \pm 0.27^{\mathrm{b}}$ & $8.18 \pm 0.16^{\mathrm{c}}$ & $8.57 \pm 0.28^{\mathrm{b}}$ & $9.26 \pm 0.26^{\mathrm{c}}$ \\
\hline Shigella flexneri & $8.63 \pm 0.32^{\mathrm{c}}$ & $9.47 \pm 0.26^{\mathrm{c}}$ & $8.30 \pm 0.84^{\mathrm{b}}$ & $10.29 \pm 0.25^{\mathrm{c}}$ \\
\hline Enterobacter aerogenes & $9.25 \pm 0.31^{\mathrm{b}}$ & $8.60 \pm 0.30^{\mathrm{b}}$ & $9.28 \pm 0.31^{\mathrm{b}}$ & $9.25 \pm 0.31^{\mathrm{c}}$ \\
\hline Salmonella typhi & $9.50 \pm 0.26^{\mathrm{c}}$ & $9.22 \pm 0.22^{\mathrm{c}}$ & $8.53 \pm 0.28^{\mathrm{b}}$ & $9.65 \pm 0.30^{\mathrm{c}}$ \\
\hline Shigella sonnei & $9.66 \pm 0.28^{\mathrm{c}}$ & $9.09 \pm 0.16^{\mathrm{bc}}$ & $8.66 \pm 0.33^{\mathrm{b}}$ & $10.33 \pm 0.24^{\mathrm{d}}$ \\
\hline Citrobacter freundii & $9.53 \pm 0.24^{\mathrm{c}}$ & $8.43 \pm 0.26^{\mathrm{b}}$ & $8.25 \pm 0.31^{\mathrm{b}}$ & $9.69 \pm 0.30^{\mathrm{d}}$ \\
\hline Streptococcus pyogenes & $10.21 \pm 0.24^{\mathrm{d}}$ & $9.33 \pm 0.28^{\mathrm{c}}$ & $7.80 \pm 0.15^{\mathrm{b}}$ & $10.65 \pm 0.24^{\mathrm{c}}$ \\
\hline Serrattia marcescens & $9.57 \pm 0.28^{\mathrm{c}}$ & $9.09 \pm 0.55^{\mathrm{c}}$ & $7.52 \pm 0.28^{\mathrm{b}}$ & $10.67 \pm 0.39^{\mathrm{c}}$ \\
\hline Pseudomonas aeruginosa & $9.29 \pm 0.28^{\mathrm{c}}$ & $8.30 \pm 0.31^{\mathrm{b}}$ & $8.40 \pm 0.31^{\mathrm{b}}$ & $10.32 \pm 0.33^{\mathrm{d}}$ \\
\hline Proteus mirabilis & $8.60 \pm 0.27^{\mathrm{b}}$ & $8.30 \pm 0.31^{\mathrm{b}}$ & $8.20 \pm 0.30^{\mathrm{b}}$ & $9.33 \pm 0.30^{\mathrm{c}}$ \\
\hline
\end{tabular}




\begin{tabular}{|l|l|l|l|l|}
\hline & \multicolumn{1}{|c|}{ A } & \multicolumn{1}{c|}{ B } & \multicolumn{1}{c|}{ C } & \multicolumn{1}{c|}{ D } \\
\hline Staphylococcus epidermidis & $9.53 \pm 0.29^{\mathrm{c}}$ & $9.83 \pm 0.17^{\mathrm{c}}$ & $7.57 \pm 0.28^{\mathrm{b}}$ & $9.40 \pm 0.30^{\mathrm{c}}$ \\
\hline Staphylococcus aureus & $10.46 \pm 0.23^{\mathrm{c}}$ & $8.75 \pm 0.23^{\mathrm{b}}$ & $9.57 \pm 0.28^{\mathrm{c}}$ & $11.57 \pm 0.30^{\mathrm{c}}$ \\
\hline Bacillus subtilis & $9.42 \pm 0.20^{\mathrm{c}}$ & $9.33 \pm 0.29^{\mathrm{b}}$ & $8.69 \pm 0.25^{\mathrm{b}}$ & $9.50 \pm 0.21^{\mathrm{c}}$ \\
\hline Bacillus aureus & $9.46 \pm 0.24^{\mathrm{c}}$ & $8.75 \pm 0.23^{\mathrm{c}}$ & $7.57 \pm 0.28^{\mathrm{b}}$ & $9.57 \pm 0.30^{\mathrm{d}}$ \\
\hline Micrococcus luteus & $9.29 \pm 0.20^{\mathrm{c}}$ & $8.40 \pm 0.27^{\mathrm{b}}$ & $8.37 \pm 0.29^{\mathrm{b}}$ & $10.43 \pm 0.26^{\mathrm{d}}$ \\
\hline Bacillus thuringiensis & $9.47 \pm 0.26^{\mathrm{c}}$ & $8.26 \pm 0.26^{\mathrm{b}}$ & $7.66 \pm 0.288^{\mathrm{b}}$ & $10.60 \pm 0.31^{\mathrm{d}}$ \\
\hline Alcaligenes faecalis & $10.29 \pm 0.31^{\mathrm{c}}$ & $8.33 \pm 0.30^{\mathrm{b}}$ & $8.26 \pm 0.32^{\mathrm{b}}$ & $10.23 \pm 0.34^{\mathrm{c}}$ \\
\hline Staphylococcus cohnii & $9.47 \pm 0.27^{\mathrm{c}}$ & $8.46 \pm 0.26^{\mathrm{b}}$ & $7.90 \pm 0.15^{\mathrm{b}}$ & $10.53 \pm 0.26^{\mathrm{d}}$ \\
\hline
\end{tabular}

Table 1: Antibiotic Sensitivity Patterns of Bacterial Isolates

Data Are Presented as Mean \pm S.E (N=3). Values with the Same Superscript Letter(S) Along the Same Rows Are Not Significantly Different $(P<0.05)$.

KEYS: $A=$ Nitrofurantoin $(5 \mathrm{mg} / \mathrm{Ml}) B=$ Ampiclox $(5 \mathrm{mg} / \mathrm{Ml}) \mathrm{C}=$ Chloramphenicol $(5 \mathrm{mg} / \mathrm{Ml})$ $D=$ Ciprofloxacin $(5 \mathrm{mg} / \mathrm{Ml})$

\begin{tabular}{|c|c|c|c|c|c|c|}
\hline & $50 \mathrm{mg} / \mathrm{ml}$ & $\begin{array}{c}100 \\
\mathrm{mg} / \mathrm{ml}\end{array}$ & $200 \mathrm{mg} / \mathrm{ml}$ & $300 \mathrm{mg} / \mathrm{ml}$ & $\begin{array}{l}\text { Positive } \\
\text { control }\end{array}$ & $\begin{array}{c}\text { Tween } \\
20\end{array}$ \\
\hline Escherichia coli & $4.60 \pm 0.18^{a}$ & $6.06 \pm 0.98^{a}$ & $10.60 \pm 0.43^{b}$ & $15.15 \pm 0.39 c$ & $9.91 \pm 0.38^{\mathrm{d}}$ & 0 \\
\hline Klebsiella oxytoca & $3.23 \pm 0.17$ a & $5.32 \pm 0.37^{a}$ & $10.73 \pm 0.54 \mathrm{~b}$ & $14.3 \pm 0.34^{c}$ & $10.04 \pm 0.01^{\mathrm{e}}$ & 0 \\
\hline $\begin{array}{c}\text { Klebsiella } \\
\text { pneumonia }\end{array}$ & $6.52 \pm 0.10^{a}$ & $8.25 \pm 0.60$ a & $12.86 \pm 0.48^{b}$ & $17.08 \pm 0.36^{c}$ & $10.47 \pm 0.24^{d}$ & 0 \\
\hline Proteus vulgaris & $4.52 \pm 0.15^{a}$ & $6.45 \pm 0.11^{\mathrm{a}}$ & $10.49 \pm 0.56^{b}$ & $16.26 \pm 0.45^{c}$ & $9.26 \pm 0.26^{c}$ & 0 \\
\hline Shigella flexneri & $3.16 \pm 0.22^{\mathrm{a}}$ & $5.91 \pm 0.11^{\mathrm{a}}$ & $9.58 \pm 0.40^{b}$ & $16.11 \pm 0.48^{c}$ & $10.29 \pm 0.25^{c}$ & 0 \\
\hline $\begin{array}{c}\text { Enterobacter } \\
\text { aerogenes }\end{array}$ & $6.14 \pm 0.28^{a}$ & $8.41 \pm 0.32^{\mathrm{a}}$ & $11.71 \pm 0.36^{b}$ & $16.48 \pm 0.51^{c}$ & $9.25 \pm 0.31^{c}$ & 0 \\
\hline Salmonella typhi & $5.91 \pm 0.35^{a}$ & $7.39 \pm 0.53^{a}$ & $10.99 \pm 0.45^{b}$ & $16.77 \pm 0.46^{c}$ & $9.65 \pm 0.30^{c}$ & 0 \\
\hline Shigella sonnei & $4.24 \pm 0.30^{a}$ & $6.42 \pm 0.02^{a}$ & $11.00 \pm 0.57 \mathrm{~b}$ & $15.35 \pm 0.35^{c}$ & $10.33 \pm 0.24^{d}$ & 0 \\
\hline $\begin{array}{l}\text { Citrobacter } \\
\text { freundii }\end{array}$ & $3.24 \pm 0.12^{\mathrm{a}}$ & $5.42 \pm 0.21^{a}$ & $9.90 \pm 0.58^{b}$ & $14.28 \pm 0.60^{c}$ & $9.69 \pm 0.30^{\mathrm{d}}$ & 0 \\
\hline $\begin{array}{c}\text { Streptococcus } \\
\text { pyogenes }\end{array}$ & $5.52 \pm 0.29$ a & $7.25 \pm 0.28^{a}$ & $11.11 \pm 0.59^{b}$ & $16.07 \pm 0.39^{c}$ & $10.65 \pm 0.24^{c}$ & 0 \\
\hline $\begin{array}{c}\text { Serrattia } \\
\text { marcescens }\end{array}$ & $6.04 \pm 0.52^{\mathrm{a}}$ & $8.63 \pm 0.25^{a}$ & $13.23 \pm 0.46^{b}$ & $18.18 \pm 0.52^{c}$ & $10.67 \pm 0.39 c$ & 0 \\
\hline $\begin{array}{c}\text { Pseudomonas } \\
\text { aeruginosa }\end{array}$ & $6.20 \pm 0.66^{a}$ & $8.62 \pm 0.31^{a}$ & $12.98 \pm 0.33^{b}$ & $17.99 \pm 0.26^{c}$ & $10.32 \pm 0.33^{\mathrm{d}}$ & 0 \\
\hline Proteus mirabilis & $6.66 \pm 0.37 \mathrm{a}$ & $8.62 \pm 0.21^{a}$ & $12.21 \pm 0.23^{b}$ & $17.52 \pm 0.36^{c}$ & $9.33 \pm 0.30^{c}$ & 0 \\
\hline $\begin{array}{c}\text { Staphylococcus } \\
\text { epidermidis }\end{array}$ & $5.55 \pm 0.92^{\mathrm{a}}$ & $8.58 \pm 0.29 \mathrm{a}$ & $14.34 \pm 0.47 b$ & $20.56 \pm 0.70^{c}$ & $9.40 \pm 0.30^{c}$ & 0 \\
\hline Bacillus subtilis & $4.88 \pm 0.64^{a}$ & $7.38 \pm 0.27 \mathrm{a}$ & $11.66 \pm 0.33^{b}$ & $17.25 \pm 0.59^{c}$ & $9.50 \pm 0.21^{c}$ & 0 \\
\hline $\begin{array}{c}\text { Staphylococcus } \\
\text { aureus }\end{array}$ & $7.87 \pm 0.21^{\mathrm{a}}$ & $\begin{array}{c}10.56 \pm 0.29 \\
\text { a }\end{array}$ & $15.31 \pm 0.44 b$ & $20.51 \pm 0.39 c$ & $11.50 \pm 0.21^{c}$ & 0 \\
\hline $\begin{array}{c}\text { Micrococcus } \\
\text { luteus }\end{array}$ & $7.77 \pm 0.33^{\mathrm{a}}$ & $9.13 \pm 0.57 \mathrm{a}$ & $13.11 \pm 0.31^{b}$ & $20.24 \pm 0.34^{c}$ & $10.43 \pm 0.26^{\mathrm{d}}$ & 0 \\
\hline $\begin{array}{c}\text { Bacillus } \\
\text { thuringiensis }\end{array}$ & $6.01 \pm 0.86^{\mathrm{a}}$ & $8.10 \pm 0.52^{a}$ & $14.32 \pm 0.37 \mathrm{~b}$ & $18.49 \pm 0.29 c$ & $10.60 \pm 0.31^{d}$ & 0 \\
\hline $\begin{array}{l}\text { Alcaligenes } \\
\text { faecalis }\end{array}$ & $4.07 \pm 0.42^{\mathrm{a}}$ & $6.60 \pm 0.35 \mathrm{a}$ & $10.74 \pm 0.42^{b}$ & $14.07 \pm 0.46^{c}$ & $10.23 \pm 0.34^{c}$ & 0 \\
\hline $\begin{array}{c}\text { Staphylococcus } \\
\text { cohnii }\end{array}$ & $5.09 \pm 0.38^{a}$ & $7.35 \pm 0.20^{a}$ & $13.49 \pm 0.38^{b}$ & $18.44 \pm 0.58^{\mathrm{c}}$ & $10.53 \pm 0.26^{\mathrm{d}}$ & 0 \\
\hline Bacillus aureus & $4.19 \pm 0.19 \mathrm{a}$ & $6.59 \pm 0.30^{a}$ & $13.06 \pm 0.29 b$ & $18.04 \pm 0.58^{c}$ & $9.57 \pm 0.30^{c}$ & 0 \\
\hline
\end{tabular}

Table 2: Sensitivity Patterns of Bacterial Isolates to Methanol Extracts of Ocimum Gratissimum

\begin{tabular}{|c|c|c|c|c|c|c|}
\hline & $\mathbf{5 0} \mathbf{~ m g} / \mathbf{m l}$ & $\mathbf{1 0 0} \mathbf{m g} / \mathbf{m l}$ & $\mathbf{2 0 0 \mathbf { m g }} / \mathbf{m l}$ & $\mathbf{3 0 0} \mathbf{m g} / \mathbf{m l}$ & Positive control & Tween 20 \\
\hline Escherichia coli & $2.13 \pm 0.11^{\mathrm{b}}$ & $4.99 \pm 0.10^{\mathrm{a}}$ & $9.48 \pm 0.43^{\mathrm{c}}$ & $16.63 \pm 0.44^{\mathrm{c}}$ & $9.91 \pm 0.38^{\mathrm{d}}$ & 0 \\
\hline Klebsiella oxytoca & $3.34 \pm 0.10^{\mathrm{a}}$ & $6.78 \pm 0.10^{\mathrm{a}}$ & $10.24 \pm 0.39^{\mathrm{c}}$ & $16.37 \pm 0.71^{\mathrm{c}}$ & $10.04 \pm 0.01^{\mathrm{e}}$ & 0 \\
\hline $\begin{array}{c}\text { Klebsiella } \\
\text { pneumonia }\end{array}$ & $2.19 \pm 0.32^{\mathrm{b}}$ & $4.11 \pm 0.12^{\mathrm{a}}$ & $9.04 \pm 0.47^{\mathrm{c}}$ & $14.83 \pm 0.45^{\mathrm{c}}$ & $10.47 \pm 0.24^{\mathrm{d}}$ & 0 \\
\hline Proteus vulgaris & $3.11 \pm 0.10^{\mathrm{b}}$ & $6.11 \pm 0.10^{\mathrm{a}}$ & $10.01 \pm 0.35^{\mathrm{c}}$ & $14.44 \pm 0.32^{\mathrm{c}}$ & $9.26 \pm 0.26^{\mathrm{c}}$ & 0 \\
\hline Shigella flexneri & $2.00 \pm 0.12^{\mathrm{a}}$ & $3.90 \pm 0.10^{\mathrm{b}}$ & $8.50 \pm 0.33^{\mathrm{a}}$ & $15.33 \pm 0.48^{\mathrm{c}}$ & $10.29 \pm 0.25^{\mathrm{c}}$ & 0 \\
\hline $\begin{array}{c}\text { Enterobacter } \\
\text { aerogenes }\end{array}$ & $5.62 \pm 0.78^{\mathrm{a}}$ & $7.00 \pm 0.15^{\mathrm{b}}$ & $10.88 \pm 0.58^{\mathrm{b}}$ & $17.53 \pm 0.66^{\mathrm{b}}$ & $9.25 \pm 0.31^{\mathrm{c}}$ & 0 \\
\hline Salmonella typhi & $3.31 \pm 0.53^{\mathrm{a}}$ & $6.00 \pm 0.12^{\mathrm{a}}$ & $11.90 \pm 0.52^{\mathrm{b}}$ & $15.40 \pm 0.59^{\mathrm{c}}$ & $9.65 \pm 0.30^{\mathrm{c}}$ & 0 \\
\hline
\end{tabular}




\begin{tabular}{|c|c|c|c|c|c|c|}
\hline & $\mathbf{5 0} \mathbf{~ m g} / \mathbf{m l}$ & $\mathbf{1 0 0} \mathbf{m g} / \mathbf{m l}$ & $\mathbf{2 0 0} \mathbf{m g} / \mathbf{m l}$ & $\mathbf{3 0 0} \mathbf{m g} / \mathbf{m l}$ & Positive control & Tween 20 \\
\hline Shigella sonnei & $5.09 \pm 0.13^{\mathrm{a}}$ & $7.10 \pm 0.12^{\mathrm{b}}$ & $11.32 \pm 0.7^{\mathrm{c}}$ & $16.89 \pm 0.89^{\mathrm{a}}$ & $9.20 \pm 0.27^{\mathrm{c}}$ & 0 \\
\hline Citrobacter freundii & $3.21 \pm 0.41^{\mathrm{b}}$ & $5.20 \pm 0.10^{\mathrm{a}}$ & $10.60 \pm 0.63^{\mathrm{b}}$ & $17.80 \pm 0.29^{\mathrm{c}}$ & $10.33 \pm 0.24^{\mathrm{d}}$ & 0 \\
\hline $\begin{array}{c}\text { Streptococcus } \\
\text { pyogenes }\end{array}$ & $4.00 \pm 0.10^{\mathrm{b}}$ & $7.31 \pm 0.10^{\mathrm{a}}$ & $11.40 \pm 0.81^{\mathrm{b}}$ & $15.5 \pm 0.47^{\mathrm{b}}$ & $9.69 \pm 0.30^{\mathrm{d}}$ & 0 \\
\hline $\begin{array}{c}\text { Serrattia } \\
\text { marcescens }\end{array}$ & $3.21 \pm 0.11^{\mathrm{b}}$ & $6.10 \pm 0.10^{\mathrm{a}}$ & $10.49 \pm 0.65^{\mathrm{b}}$ & $15.65 \pm 0.43^{\mathrm{c}}$ & $10.65 \pm 0.24^{\mathrm{c}}$ & 0 \\
\hline $\begin{array}{c}\text { Pseudomonas } \\
\text { aeruginosa }\end{array}$ & $2.22 \pm 0.31^{\mathrm{b}}$ & $4.30 \pm 0.10^{\mathrm{a}}$ & $9.00 \pm 0.58^{\mathrm{c}}$ & $15.90 \pm 0.29^{\mathrm{b}}$ & $10.67 \pm 0.39^{\mathrm{c}}$ & 0 \\
\hline Proteus mirabilis & $1.05 \pm 0.21^{\mathrm{b}}$ & $3.67 \pm 0.10^{\mathrm{a}}$ & $8.11 \pm 0.55^{\mathrm{c}}$ & $14.99 \pm 0.27^{\mathrm{c}}$ & $10.32 \pm 0.33^{\mathrm{d}}$ & 0 \\
\hline $\begin{array}{c}\text { Staphylococcus } \\
\text { epidermidis }\end{array}$ & $5.02 \pm 0.21^{\mathrm{b}}$ & $7.30 \pm 0.10^{\mathrm{a}}$ & $11.41 \pm 0.32^{\mathrm{c}}$ & $16.54 \pm 0.30^{\mathrm{c}}$ & $9.33 \pm 0.30^{\mathrm{c}}$ & 0 \\
\hline $\begin{array}{c}\text { Bacillus subtilis } \\
\text { Staphylococcus } \\
\text { aureus }\end{array}$ & $4.00 \pm 0.23^{\mathrm{b}}$ & $6.02 \pm 0.10^{\mathrm{a}}$ & $12.4 \pm 0.60^{\mathrm{c}}$ & $18.42 \pm 0.28^{\mathrm{b}}$ & $9.40 \pm 0.30^{\mathrm{c}}$ & 0 \\
\hline Micrococcus luteus & $2.21 \pm 0.12^{\mathrm{b}}$ & $4.60 \pm 0.10^{\mathrm{a}}$ & $8.20 \pm 0.39^{\mathrm{c}}$ & $15.94 \pm 0.54^{\mathrm{c}}$ & $9.50 \pm 0.21^{\mathrm{c}}$ & 0 \\
\hline $\begin{array}{c}\text { Bacillus } \\
\text { thuringiensis }\end{array}$ & $5.19 \pm 0.21^{\mathrm{b}}$ & $7.23 \pm 0.10^{\mathrm{a}}$ & $11.43 \pm 0.55^{\mathrm{c}}$ & $16.41 \pm 0.45^{\mathrm{c}}$ & $9.57 \pm 0.30^{\mathrm{d}}$ & 0 \\
\hline Alcaligenes faecalis & $2.98 \pm 0.10^{\mathrm{b}}$ & $5.50 \pm 0.10^{\mathrm{a}}$ & $9.49 \pm 0.80^{\mathrm{b}}$ & $14.06 \pm 0.28^{\mathrm{c}}$ & $10.43 \pm 0.26^{\mathrm{d}}$ & 0 \\
\hline $\begin{array}{c}\text { Staphylococcus } \\
\text { cohnii }\end{array}$ & $3.33 \pm 0.37^{\mathrm{b}}$ & $5.62 \pm 0.10^{\mathrm{a}}$ & $10.17 \pm 0.60^{\mathrm{c}}$ & $16.14 \pm 0.53^{\mathrm{b}}$ & $10.6 \pm 0.31^{\mathrm{d}}$ & 0 \\
\hline Bacillus aureus & $4.21 \pm 0.63^{\mathrm{b}}$ & $6.51 \pm 0.10^{\mathrm{a}}$ & $12.42 \pm 0.68^{\mathrm{b}}$ & $16.48 \pm 0.44^{\mathrm{b}}$ & $10.23 \pm 0.34^{\mathrm{c}}$ & 0 \\
\hline
\end{tabular}

Table 3: In-Vitro Sensitivity Profile of Bacterial Isolates Treated with Water Extracts of Ocimum Gratissimum KEY: Positive Control= Ciprofloxacin $(5 \mathrm{mg} / \mathrm{Ml})$

\begin{tabular}{|c|c|c|c|c|c|c|}
\hline & $50 \mathrm{mg} / \mathrm{ml}$ & $100 \mathrm{mg} / \mathrm{ml}$ & $200 \mathrm{mg} / \mathrm{ml}$ & $300 \mathrm{mg} / \mathrm{ml}$ & $\begin{array}{l}\text { Positive } \\
\text { control }\end{array}$ & Tween 20 \\
\hline Escherichia coli & $1.06 \pm 0.14^{\mathrm{a}}$ & $3.08 \pm 0.12^{\mathrm{a}}$ & $4.85 \pm 0.27^{\mathrm{b}}$ & $8.13 \pm 0.19^{c}$ & $9.91 \pm 0.38^{\mathrm{d}}$ & 0 \\
\hline $\begin{array}{c}\text { Klebsiella } \\
\text { oxytoca }\end{array}$ & $1.09 \pm 0.21^{\mathrm{a}}$ & $3.42 \pm 0.30^{\text {a }}$ & $5.50 \pm .0 .26^{b}$ & $7.01 \pm 0 . .34^{c}$ & $10.04 \pm 0.01^{\mathrm{e}}$ & 0 \\
\hline $\begin{array}{c}\text { Klebsiella } \\
\text { pneumonia }\end{array}$ & $1.00 \pm 0.19 \mathrm{a}$ & $1.80 \pm 0.34^{a}$ & $4.05 \pm 0.13^{\mathrm{b}}$ & $7.07 \pm 0.98^{c}$ & $10.47 \pm 0.24^{\mathrm{d}}$ & 0 \\
\hline Proteus vulgaris & $1.12 \pm 0.13^{\mathrm{a}}$ & $3.37 \pm 0.35^{\text {a }}$ & $5.36 \pm 0.35^{b}$ & $8.22 \pm 0.12^{c}$ & $9.26 \pm 0.26^{c}$ & 0 \\
\hline Shigella flexneri & $1.81 \pm 0.14^{\mathrm{a}}$ & $3.08 \pm 0.17 \mathrm{a}$ & $4.94 \pm 0.24^{b}$ & $7.06 \pm 0.41^{\mathrm{c}}$ & $10.29 \pm 0.25^{c}$ & 0 \\
\hline $\begin{array}{c}\text { Enterobacter } \\
\text { aerogenes }\end{array}$ & $1.11 \pm 0.12^{\mathrm{a}}$ & $2.83 \pm 0.17 \mathrm{a}$ & $5.15 \pm 0.34 \mathrm{~b}$ & $7.99 \pm 0.29 \mathrm{c}$ & $9.25 \pm 0.31^{c}$ & 0 \\
\hline Salmonella typhi & $1.21 \pm 0.21^{\mathrm{a}}$ & $3.50 \pm 0.26^{a}$ & $5.34 \pm 0.21^{b}$ & $7.13 \pm 0.15^{c}$ & $9.65 \pm 0.30^{c}$ & 0 \\
\hline Shigella sonnei & $1.18 \pm 0.87^{a}$ & $2.83 \pm 0.17$ a & $4.97 \pm 0.38^{b}$ & $7.47 \pm 0.29^{c}$ & $9.20 \pm 0.27 \mathrm{c}$ & 0 \\
\hline $\begin{array}{c}\text { Citrobacter } \\
\text { freundii }\end{array}$ & $1.17 \pm 0.41^{\mathrm{a}}$ & $2.90 \pm 0.50^{a}$ & $5.13 \pm 0.75^{b}$ & $7.17 \pm 0.27 \mathrm{c}$ & $10.33 \pm 0.24^{\mathrm{d}}$ & 0 \\
\hline $\begin{array}{l}\text { Streptococcus } \\
\text { pyogenes }\end{array}$ & $1.90 \pm 0.19 \mathrm{a}$ & $2.07 \pm 0.17 \mathrm{a}$ & $4.67 \pm 0.27^{b}$ & $6.21 \pm 0.15^{c}$ & $9.69 \pm 0.30^{\mathrm{d}}$ & 0 \\
\hline $\begin{array}{c}\text { Serrattia } \\
\text { marcescens }\end{array}$ & $1.03 \pm 0.12^{\mathrm{a}}$ & $3.22 \pm 0.14^{a}$ & $5.29 \pm 0.18^{b}$ & $7.28 \pm 0.19^{c}$ & $10.65 \pm 0.24^{c}$ & 0 \\
\hline $\begin{array}{c}\text { Pseudomonas } \\
\text { aeruginosa }\end{array}$ & $1.21 \pm 0.04^{\mathrm{a}}$ & $3.50 \pm 0.01^{a}$ & $5.42 \pm 0.24^{b}$ & $7.40 \pm 0.26^{c}$ & $10.67 \pm 0.39^{c}$ & 0 \\
\hline Proteus mirabilis & $1.32 \pm 0.09^{a}$ & $2.40 \pm 0.22^{\mathrm{a}}$ & $4.22 \pm 0.23^{b}$ & $5.99 \pm 0.16^{c}$ & $10.32 \pm 0.33^{\mathrm{d}}$ & 0 \\
\hline $\begin{array}{l}\text { Staphylococcus } \\
\text { epidermidis }\end{array}$ & $1.32 \pm 0.21^{\mathrm{a}}$ & $3.57 \pm 0.30^{\text {a }}$ & $7.12 \pm 0.16^{b}$ & $8.53 \pm 0.58^{\mathrm{c}}$ & $9.33 \pm 0.30^{c}$ & 0 \\
\hline $\begin{array}{c}\text { Staphylococcus } \\
\text { aureus }\end{array}$ & $2.31 \pm 0.18^{\mathrm{a}}$ & $4.02 \pm 0.40^{a}$ & $7.52 \pm 0.26^{b}$ & $9.13 \pm 0.35^{c}$ & $11.40 \pm 0.30^{c}$ & 0 \\
\hline Bacillus subtilis & $1.15 \pm 0.21^{\mathrm{a}}$ & $3.12 \pm 0.18^{a}$ & $5.10 \pm 0.14^{b}$ & $6.6 \pm 0.21^{c}$ & $9.57 \pm 0.30^{c}$ & 0 \\
\hline Bacillus aureus & $1.32 \pm 0.27^{a}$ & $3.70 \pm 0.37 \mathrm{a}$ & $5.05 \pm 0.15^{b}$ & $5.99 \pm 0.37 \mathrm{~b}$ & $9.50 \pm 0.21^{c}$ & 0 \\
\hline $\begin{array}{c}\text { Micrococcus } \\
\text { luteus }\end{array}$ & $2.01 \pm 0.31^{\mathrm{a}}$ & $4.23 \pm 0.66^{\mathrm{a}}$ & $6.15 \pm 0.25^{b}$ & $6.31 \pm 0.29^{b}$ & $9.57 \pm 0.30^{\mathrm{d}}$ & 0 \\
\hline $\begin{array}{c}\text { Bacillus } \\
\text { thuringiensis }\end{array}$ & $1.00 \pm 0.16^{\mathrm{a}}$ & $2.08 \pm 0.18^{\mathrm{a}}$ & $5.19 \pm 0.39^{b}$ & $6.33 \pm 0.21^{c}$ & $10.43 \pm 0.26^{\mathrm{d}}$ & 0 \\
\hline $\begin{array}{c}\text { Alcaligenes } \\
\text { faecalis }\end{array}$ & $1.09 \pm 0.15^{\mathrm{a}}$ & $2.14 \pm 0.14^{a}$ & $4.33 \pm 0.32^{\mathrm{b}}$ & $6.38 \pm 0.30^{c}$ & $10.6 \pm 0.31^{d}$ & 0 \\
\hline $\begin{array}{c}\text { Staphylococcus } \\
\text { cohnii }\end{array}$ & $1.56 \pm 0.12^{\mathrm{a}}$ & $3.29 \pm 0.19^{a}$ & $5.23 \pm 0.30^{\mathrm{b}}$ & $5.24 \pm 0.30^{\mathrm{b}}$ & $10.23 \pm 0.34^{c}$ & 0 \\
\hline
\end{tabular}

Table 4: Effects of Petroleum Ether Extracts of Ocimum Gratissimum on the Survival of Bacterial Isolates KEY: Positive Control= Ciprofloxacin (5mg/Ml) 


\begin{tabular}{|c|c|c|c|c|c|c|}
\hline & $50 \mathrm{mg} / \mathrm{ml}$ & $100 \mathrm{mg} / \mathrm{ml}$ & $200 \mathrm{mg} / \mathrm{ml}$ & $300 \mathrm{mg} / \mathrm{ml}$ & $\begin{array}{c}\text { Positive } \\
\text { control } \\
\end{array}$ & $\begin{array}{c}\text { Tween } \\
20 \\
\end{array}$ \\
\hline Escherichia coli & $3.03 \pm 0.35^{b}$ & $6.69 \pm 0.23^{a}$ & $9.84 \pm 0.34^{c}$ & $15.36 \pm 0.27^{c}$ & $9.91 \pm 0.38^{d}$ & 0 \\
\hline $\begin{array}{c}\text { Klebsiella } \\
\text { oxytoca }\end{array}$ & $4.02 \pm 0.14^{b}$ & $7.18 \pm 0.11^{\mathrm{a}}$ & $10.54 \pm 0.48^{c}$ & $14.73 \pm 0.76^{c}$ & $10.04 \pm 0.01^{\mathrm{e}}$ & 0 \\
\hline $\begin{array}{c}\text { Klebsiella } \\
\text { pneumonia }\end{array}$ & $3.21 \pm 0.28^{\mathrm{b}}$ & $6.11 \pm 0.12^{\mathrm{a}}$ & $10.04 \pm 0.63^{c}$ & $16.03 \pm 0.54^{c}$ & $10.47 \pm 0.24^{d}$ & 0 \\
\hline Proteus vulgaris & $2.16 \pm 0.23^{b}$ & $5.11 \pm 0.20^{\mathrm{a}}$ & $11.01 \pm 0.15^{c}$ & $15.64 \pm 0.22^{c}$ & $9.26 \pm 0.26^{c}$ & 0 \\
\hline Shigella flexneri & $5.53 \pm 0.16^{\mathrm{a}}$ & $8.03 \pm 0.13^{b}$ & $10.50 \pm 0.23^{\mathrm{a}}$ & $15.73 \pm 0.88^{c}$ & $10.29 \pm 0.25^{c}$ & 0 \\
\hline $\begin{array}{c}\text { Enterobacter } \\
\text { aerogenes }\end{array}$ & $5.22 \pm 0.12^{\mathrm{a}}$ & $7.00 \pm 0.25^{b}$ & $10.28 \pm 0.18^{b}$ & $17.59 \pm 0.26^{b}$ & $9.25 \pm 0.31^{c}$ & 0 \\
\hline Salmonella typhi & $4.01 \pm 0.31^{b}$ & $7.49 \pm 0.17 \mathrm{a}$ & $11.82 \pm 0.22^{b}$ & $16.60 \pm 0.89 \mathrm{c}$ & $9.65 \pm 0.30^{c}$ & 0 \\
\hline Shigella sonnei & $3.87 \pm 0.16^{\mathrm{a}}$ & $7.11 \pm 0.18^{b}$ & $10.32 \pm 0.16^{c}$ & $16.49 \pm 0.29$ a & $9.20 \pm 0.27 \mathrm{c}$ & 0 \\
\hline $\begin{array}{c}\text { Citrobacter } \\
\text { freundii }\end{array}$ & $2.99 \pm 0.17^{b}$ & $6.20 \pm 0.10^{\mathrm{a}}$ & $9.66 \pm 0.63^{b}$ & $15.80 \pm 0.22^{c}$ & $10.33 \pm 0.24^{\mathrm{d}}$ & 0 \\
\hline $\begin{array}{c}\text { Streptococcus } \\
\text { pyogenes }\end{array}$ & $3.91 \pm 0.12^{\mathrm{a}}$ & $7.30 \pm 0.14^{\mathrm{a}}$ & $11.40 \pm 0.87 \mathrm{~b}$ & $16.50 \pm 0.47 \mathrm{~b}$ & $9.69 \pm 0.30^{d}$ & 0 \\
\hline $\begin{array}{c}\text { Serrattia } \\
\text { marcescens }\end{array}$ & $3.28 \pm 0.11^{\mathrm{a}}$ & $6.82 \pm 0.10^{a}$ & $10.49 \pm 0.45^{b}$ & $15.60 \pm 0.33^{c}$ & $10.65 \pm 0.24 \mathrm{c}$ & 0 \\
\hline $\begin{array}{c}\text { Pseudomonas } \\
\text { aeruginosa }\end{array}$ & $3.46 \pm 0.21^{\mathrm{a}}$ & $6.66 \pm 0.10^{a}$ & $9.38 \pm 0.38^{c}$ & $14.90 \pm 0.29^{b}$ & $10.67 \pm 0.39 c$ & 0 \\
\hline Proteus mirabilis & $3.69 \pm 0.10^{\mathrm{a}}$ & $7.67 \pm 0.26^{\mathrm{a}}$ & $10.11 \pm 0.75^{c}$ & $15.99 \pm 0.28^{c}$ & $10.32 \pm 0.33^{d}$ & 0 \\
\hline $\begin{array}{c}\text { Staphylococcus } \\
\text { epidermidis }\end{array}$ & $4.62 \pm 0.12^{\mathrm{a}}$ & $8.30 \pm 0.17^{a}$ & $12.41 \pm 0.31 \mathrm{bc}$ & $17.54 \pm 0.49^{c}$ & $9.33 \pm 0.30^{c}$ & 0 \\
\hline Bacillus subtilis & $3.42 \pm 0.10^{\mathrm{a}}$ & $7.02 \pm 0.10^{a}$ & $13.40 \pm 0.40^{c}$ & $15.82 \pm 0.78^{b}$ & $9.40 \pm 0.30^{c}$ & 0 \\
\hline $\begin{array}{c}\text { Staphylococcus } \\
\text { aureus }\end{array}$ & $3.32 \pm 0.10^{\mathrm{a}}$ & $7.06 \pm 0.10^{\mathrm{a}}$ & $11.67 \pm 0.78^{b}$ & $16.01 \pm 0.23^{c}$ & $11.57 \pm 0.30^{c}$ & 0 \\
\hline $\begin{array}{c}\text { Micrococcus } \\
\text { luteus }\end{array}$ & $3.01 \pm 0.12^{\mathrm{a}}$ & $6.28 \pm 0.10^{a}$ & $10.22 \pm 0.36^{b}$ & $14.99 \pm 0.42^{a}$ & $9.50 \pm 0.21^{c}$ & 0 \\
\hline $\begin{array}{c}\text { Bacillus } \\
\text { thuringiensis }\end{array}$ & $3.21 \pm 0.18^{a}$ & $7.26 \pm 0.13^{a}$ & $12.43 \pm 0.51^{b}$ & $16.81 \pm 0.45^{c}$ & $9.57 \pm 0.30^{d}$ & 0 \\
\hline $\begin{array}{l}\text { Alcaligenes } \\
\text { faecalis }\end{array}$ & $4.01 \pm 0.11^{\mathrm{a}}$ & $6.99 \pm 0.11^{\mathrm{a}}$ & $11.29 \pm 0.70^{\mathrm{b}}$ & $15.06 \pm 0.48^{c}$ & $10.43 \pm 0.26^{d}$ & 0 \\
\hline $\begin{array}{c}\text { Staphylococcus } \\
\text { cohnii }\end{array}$ & $4.20 \pm 0.12^{\mathrm{a}}$ & $8.69 \pm 0.14^{a}$ & $11.18 \pm 0.60^{b}$ & $16.14 \pm 0.53 \mathrm{~b}$ & $10.6 \pm 0.31^{d}$ & 0 \\
\hline Bacillus aureus & $3.39 \pm 0.19^{a}$ & $6.51 \pm 0.10^{a}$ & $12.42 \pm 0.68^{b}$ & $16.48 \pm 0.44 \mathrm{~b}$ & $10.23 \pm 0.34^{c}$ & 0 \\
\hline
\end{tabular}

Table 5: In-Vitro Sensitivity Patterns of Bacterial Isolates Treated with Methanol Extracts of Annona Muricata KEY: Positive Control= Ciprofloxacin $(5 \mathrm{mg} / \mathrm{Ml})$

\begin{tabular}{|c|c|c|c|c|c|c|}
\hline & $50 \mathrm{mg} / \mathrm{ml}$ & $\begin{array}{c}100 \\
\mathrm{mg} / \mathrm{ml}\end{array}$ & $200 \mathrm{mg} / \mathrm{ml}$ & $300 \mathrm{mg} / \mathrm{ml}$ & $\begin{array}{c}\text { Positive } \\
\text { Control } \\
\end{array}$ & $\begin{array}{c}\text { Tween } \\
20 \\
\end{array}$ \\
\hline Escherichia coli & $2.23 \pm 0.19^{\mathrm{a}}$ & $4.59 \pm 0.13^{a}$ & $7.42 \pm 0.94^{c}$ & $12.36 \pm 0.88^{b}$ & $9.91 \pm 0.38^{\mathrm{d}}$ & 0 \\
\hline $\begin{array}{c}\text { Klebsiella } \\
\text { oxytoca }\end{array}$ & $1.98 \pm 0.12^{\mathrm{a}}$ & $3.98 \pm 0.20^{a}$ & $7.04 \pm 0.38^{c}$ & $11.13 \pm 0.28^{c}$ & $10.04 \pm 0.01^{\mathrm{e}}$ & 0 \\
\hline $\begin{array}{c}\text { Klebsiella } \\
\text { pneumonia }\end{array}$ & $1.32 \pm 0.17^{a}$ & $3.45 \pm 0.28^{a}$ & $6.73 \pm 0.28^{c}$ & $10.22 \pm 031^{c}$ & $10.47 \pm 0.24^{\mathrm{d}}$ & 0 \\
\hline Proteus vulgaris & $2.01 \pm 0.15^{\mathrm{a}}$ & $4.13 \pm 0.20^{a}$ & $9.09 \pm 0.83^{c}$ & $12.32 \pm 0.24^{c}$ & $9.26 \pm 0.26^{c}$ & 0 \\
\hline Shigella flexneri & $1.09 \pm 0.15^{\mathrm{a}}$ & $3.06 \pm 0.13 \mathrm{~b}$ & $7.76 \pm 0.96^{a}$ & $11.40 \pm 0.88^{c}$ & $10.29 \pm 0.25^{c}$ & 0 \\
\hline $\begin{array}{c}\text { Enterobacter } \\
\text { aerogenes }\end{array}$ & $2.50 \pm 0.12^{\mathrm{a}}$ & $5.00 \pm 0.25 \mathrm{~b}$ & $9.28 \pm 0.19 b$ & $14.59 \pm 0.60^{c}$ & $9.25 \pm 0.31^{c}$ & 0 \\
\hline $\begin{array}{l}\text { Salmonella } \\
\text { typhi }\end{array}$ & $2.23 \pm 0.13^{\mathrm{a}}$ & $4.49 \pm 0.17 \mathrm{a}$ & $9.82 \pm 0.22^{b}$ & $13.60 \pm 0.89 \mathrm{c}$ & $9.65 \pm 0.30^{c}$ & 0 \\
\hline Shigella sonnei & $2.02 \pm 0.12^{\mathrm{a}}$ & $4.11 \pm 0.18^{b}$ & $10.39 \pm 0.16^{\mathrm{c}}$ & $12.59 \pm 0.29 \mathrm{a}$ & $9.20 \pm 0.27 \mathrm{c}$ & 0 \\
\hline $\begin{array}{c}\text { Citrobacter } \\
\text { freundii }\end{array}$ & $1.09 \pm 0.17^{\mathrm{a}}$ & $3.24 \pm 0.14^{\mathrm{a}}$ & $5.99 \pm 0.43^{\mathrm{C}}$ & $9.80 \pm 0.72^{c}$ & $10.33 \pm 0.24^{d}$ & 0 \\
\hline $\begin{array}{c}\text { Streptococcus } \\
\text { pyogenes }\end{array}$ & $1.21 \pm 0.19^{\mathrm{a}}$ & $3.30 \pm 0.14^{\mathrm{a}}$ & $8.60 \pm 0.87^{b}$ & $11.53 \pm 0.27^{c}$ & $9.69 \pm 0.30^{d}$ & 0 \\
\hline $\begin{array}{c}\text { Serrattia } \\
\text { marcescens }\end{array}$ & $1.23 \pm 0.10^{\mathrm{a}}$ & $3.33 \pm 0.10^{a}$ & $7.49 \pm 0.45^{b}$ & $11.60 \pm 0.33^{c}$ & $10.65 \pm 0.24 \mathrm{c}$ & 0 \\
\hline $\begin{array}{c}\text { Pseudomonas } \\
\text { aeruginosa }\end{array}$ & $1.45 \pm 0.18^{a}$ & $3.66 \pm 0.10^{a}$ & $6.38 \pm 0.38^{c}$ & $10.90 \pm 0.29 b$ & $10.67 \pm 0.39 c$ & 0 \\
\hline $\begin{array}{c}\text { Proteus } \\
\text { mirabilis }\end{array}$ & $2.22 \pm 0.29^{a}$ & $4.19 \pm 0.26^{a}$ & $8.11 \pm 0.75^{c}$ & $12.99 \pm 0.98^{c}$ & $10.32 \pm 0.33^{\mathrm{d}}$ & 0 \\
\hline
\end{tabular}




\begin{tabular}{|c|c|c|c|c|c|c|}
\hline & $\mathbf{5 0} \mathbf{~ m g} / \mathbf{m l}$ & $\begin{array}{c}\mathbf{1 0 0} \\
\mathbf{m g} / \mathbf{m l}\end{array}$ & $\mathbf{2 0 0} \mathbf{~ m g} / \mathbf{m l}$ & $\mathbf{3 0 0} \mathbf{~ m g} / \mathbf{m l}$ & $\begin{array}{c}\text { Positive } \\
\text { Control }\end{array}$ & $\begin{array}{c}\text { Tween } \\
\mathbf{2 0}\end{array}$ \\
\hline $\begin{array}{c}\text { Staphylococcus } \\
\text { epidermidis }\end{array}$ & $2.78 \pm 0.12^{\mathrm{a}}$ & $5.50 \pm 0.19^{\mathrm{a}}$ & $9.41 \pm 0.31^{\mathrm{b}}$ & $15.54 \pm 0.4^{\mathrm{c}}$ & $9.33 \pm 0.30^{\mathrm{c}}$ & 0 \\
\hline Bacillus subtilis & $1.90 \pm 0.15^{\mathrm{a}}$ & $3.02 \pm 0.10^{\mathrm{a}}$ & $7.40 \pm 0.40^{\mathrm{c}}$ & $10.22 \pm 0.38^{\mathrm{b}}$ & $9.40 \pm 0.30^{\mathrm{c}}$ & 0 \\
\hline $\begin{array}{c}\text { Staphylococcus } \\
\text { aureus }\end{array}$ & $2.91 \pm 0.19^{\mathrm{a}}$ & $4.02 \pm 0.13^{\mathrm{a}}$ & $8.67 \pm 0.48^{\mathrm{b}}$ & $11.01 \pm 0.3^{\mathrm{c}}$ & $10.57 \pm 0.30^{\mathrm{c}}$ & 0 \\
\hline $\begin{array}{c}\text { Micrococcus } \\
\text { luteus }\end{array}$ & $2.22 \pm 0.11^{\mathrm{a}}$ & $4.18 \pm 0.10^{\mathrm{a}}$ & $8.22 \pm 0.26^{\mathrm{b}}$ & $11.99 \pm 0.42^{\mathrm{a}}$ & $9.50 \pm 0.21^{\mathrm{c}}$ & 0 \\
\hline $\begin{array}{c}\text { Bacillus } \\
\text { thuringiensis }\end{array}$ & $1.32 \pm 0.12^{\mathrm{a}}$ & $3.06 \pm 0.13^{\mathrm{a}}$ & $7.43 \pm 0.51^{\mathrm{c}}$ & $12.81 \pm 0.45^{\mathrm{c}}$ & $9.57 \pm 0.30^{\mathrm{d}}$ & 0 \\
\hline $\begin{array}{c}\text { Alcaligenes } \\
\text { faecalis }\end{array}$ & $1.45 \pm 0.20^{\mathrm{a}}$ & $3.99 \pm 0.11^{\mathrm{a}}$ & $8.29 \pm 0.70^{\mathrm{b}}$ & $10.06 \pm 0.31^{\mathrm{c}}$ & $10.43 \pm 0.26^{\mathrm{d}}$ & 0 \\
\hline $\begin{array}{c}\text { Staphylococcus } \\
\text { cohnii }\end{array}$ & $2.33 \pm 0.21^{\mathrm{a}}$ & $4.92 \pm 0.11^{\mathrm{a}}$ & $9.18 \pm 0.73^{\mathrm{b}}$ & $12.14 \pm 0.53^{\mathrm{b}}$ & $10.6 \pm 0.31^{\mathrm{d}}$ & 0 \\
\hline Bacillus aureus & $2.81 \pm 0.24^{\mathrm{a}}$ & $4.18 \pm 0.27^{\mathrm{a}}$ & $8.42 \pm 0.28^{\mathrm{b}}$ & $11.59 \pm 0.44^{\mathrm{b}}$ & $10.23 \pm 0.34^{\mathrm{c}}$ & 0 \\
\hline
\end{tabular}

Table 6: Sensitivity Profile of Bacterial Isolates to Water Extracts of Annona Muricata KEY: Positive Control= Ciprofloxacin (5mg/MI)

\begin{tabular}{|c|c|c|c|c|c|c|}
\hline & $50 \mathrm{mg} / \mathrm{ml}$ & $100 \mathrm{mg} / \mathrm{ml}$ & $200 \mathrm{mg} / \mathrm{ml}$ & $300 \mathrm{mg} / \mathrm{ml}$ & $\begin{array}{c}\text { Positive } \\
\text { control }\end{array}$ & Tween 20 \\
\hline Escherichia coli & $2.23 \pm 0.18^{b}$ & $5.69 \pm 0.26^{\mathrm{a}}$ & $8.99 \pm 0.75^{b}$ & $14.29 \pm 0.27^{c}$ & $9.91 \pm 0.38^{\mathrm{d}}$ & 0 \\
\hline $\begin{array}{c}\text { Klebsiella } \\
\text { oxytoca }\end{array}$ & $2.91 \pm 0.18^{\mathrm{a}}$ & $5.18 \pm 0.11^{\mathrm{a}}$ & $8.22 \pm 0.48^{b}$ & $13.73 \pm 0.56^{c}$ & $10.04 \pm 0.01^{\mathrm{e}}$ & 0 \\
\hline $\begin{array}{c}\text { Klebsiella } \\
\text { pneumonia }\end{array}$ & $3.33 \pm 0.19^{a}$ & $6.71 \pm 0.12^{\mathrm{a}}$ & $10.14 \pm 0.63^{c}$ & $16.03 \pm 0.54^{c}$ & $10.47 \pm 0.24^{\mathrm{d}}$ & 0 \\
\hline $\begin{array}{l}\text { Proteus } \\
\text { vulgaris }\end{array}$ & $2.91 \pm 0.16^{\mathrm{ab}}$ & $5.11 \pm 0.14 \mathrm{a}$ & $11.11 \pm 0.44^{c}$ & $17.64 \pm 0.62 \mathrm{~b}$ & $9.26 \pm 0.26^{c}$ & 0 \\
\hline Shigella flexneri & $5.06 \pm 0.19^{a}$ & $8.03 \pm 0.13^{b}$ & $10.50 \pm 0.23^{a}$ & $15.73 \pm 0.88^{c}$ & $10.29 \pm 0.25^{c}$ & 0 \\
\hline $\begin{array}{c}\text { Enterobacter } \\
\text { aerogenes }\end{array}$ & $3.83 \pm 0.18^{a}$ & $6.10 \pm 0.45^{b}$ & $12.30 \pm 0.24 \mathrm{~b}$ & $16.91 \pm 0.26^{b}$ & $9.25 \pm 0.31^{c}$ & 0 \\
\hline $\begin{array}{c}\text { Salmonella } \\
\text { typhi }\end{array}$ & $2.71 \pm 0.19 a$ & $5.44 \pm 0.33^{a}$ & $10.62 \pm 0.12^{c}$ & $16.90 \pm 0.23^{c}$ & $9.65 \pm 0.30^{c}$ & 0 \\
\hline Shigella sonnei & $3.91 \pm 0.15^{b}$ & $6.11 \pm 0.48^{a}$ & $12.32 \pm 0.66^{c}$ & $16.59 \pm 0.22^{\mathrm{a}}$ & $9.20 \pm 0.27 c$ & 0 \\
\hline $\begin{array}{c}\text { Citrobacter } \\
\text { freundii }\end{array}$ & $3.01 \pm 0.17^{a}$ & $6.20 \pm 0.10^{a}$ & $9.66 \pm 0.63^{b}$ & $15.80 \pm 0.82^{c}$ & $10.33 \pm 0.24^{d}$ & 0 \\
\hline $\begin{array}{c}\text { Streptococcus } \\
\text { pyogenes }\end{array}$ & $2.41 \pm 0.13^{b}$ & $5.30 \pm 0.10^{\mathrm{a}}$ & $10.40 \pm 0.17^{b}$ & $14.51 \pm 0.74^{b}$ & $9.69 \pm 0.30^{d}$ & 0 \\
\hline $\begin{array}{c}\text { Serrattia } \\
\text { marcescens }\end{array}$ & $2.09 \pm 0.19^{a}$ & $4.02 \pm 0.10^{\mathrm{a}}$ & $8.39 \pm 0.88^{c}$ & $13.61 \pm 0.33^{c}$ & $10.65 \pm 0.24 c$ & 0 \\
\hline $\begin{array}{c}\text { Pseudomonas } \\
\text { aeruginosa }\end{array}$ & $2.18 \pm 0.13^{a}$ & $5.66 \pm 0.10^{a}$ & $10.38 \pm 0.34^{c}$ & $14.62 \pm 0.24^{b}$ & $10.67 \pm 0.39 c$ & 0 \\
\hline $\begin{array}{c}\text { Proteus } \\
\text { mirabilis } \\
\end{array}$ & $3.20 \pm 0.18^{a}$ & $6.97 \pm 0.26^{a}$ & $11.11 \pm 0.84^{c}$ & $15.99 \pm 0.28^{c}$ & $10.32 \pm 0.33^{d}$ & 0 \\
\hline $\begin{array}{c}\text { Staphylococcus } \\
\text { epidermidis }\end{array}$ & $4.72 \pm 0.17^{b}$ & $7.70 \pm 0.14^{a}$ & $12.45 \pm 0.31 \mathrm{bc}$ & $16.84 \pm 0.42^{c}$ & $9.33 \pm 0.30^{c}$ & 0 \\
\hline Bacillus subtilis & $3.00 \pm 0.12^{b}$ & $5.72 \pm 0.13^{a}$ & $10.44 \pm 0.40^{\mathrm{b}}$ & $16.10 \pm 0.72^{b}$ & $9.40 \pm 0.30^{c}$ & 0 \\
\hline $\begin{array}{c}\text { Staphylococcus } \\
\text { aureus }\end{array}$ & $4.21 \pm 0.16^{\mathrm{a}}$ & $7.11 \pm 0.10^{\mathrm{a}}$ & $13.07 \pm 0.78^{b}$ & $18.01 \pm 0.23^{b}$ & $11.57 \pm 0.30^{c}$ & 0 \\
\hline $\begin{array}{c}\text { Micrococcus } \\
\text { luteus }\end{array}$ & $3.82 \pm 0.14^{a}$ & $6.66 \pm 0.17 \mathrm{a}$ & $11.92 \pm 0.36^{b}$ & $14.99 \pm 0.42^{\mathrm{a}}$ & $9.50 \pm 0.21^{c}$ & 0 \\
\hline $\begin{array}{c}\text { Bacillus } \\
\text { thuringiensis }\end{array}$ & $4.21 \pm 0.19 \mathrm{a}$ & $7.26 \pm 0.13^{a}$ & $12.43 \pm 0.51^{b}$ & $15.88 \pm 0.85^{c}$ & $9.57 \pm 0.30^{\mathrm{d}}$ & 0 \\
\hline $\begin{array}{c}\text { Alcaligenes } \\
\text { faecalis }\end{array}$ & $3.24 \pm 0.19 \mathrm{a}$ & $6.52 \pm 0.11^{\mathrm{a}}$ & $10.29 \pm 0.40^{b}$ & $15.06 \pm 0.48^{c}$ & $10.43 \pm 0.26^{\mathrm{d}}$ & 0 \\
\hline $\begin{array}{c}\text { Staphylococcus } \\
\text { cohnii }\end{array}$ & $4.21 \pm 0.17^{b}$ & $7.77 \pm 0.39^{a}$ & $12.28 \pm 0.60^{c}$ & $17.24 \pm 0.35^{b}$ & $10.6 \pm 0.31^{d}$ & 0 \\
\hline Bacillus aureus & $3.38 \pm 0.13^{a}$ & $7.51 \pm 0.20^{a}$ & $11.12 \pm 0.55^{b}$ & $16.48 \pm 0.51^{c}$ & $10.23 \pm 0.34^{c}$ & 0 \\
\hline
\end{tabular}

Table 7: Sensitivity Patterns of the Bacterial Isolates Exposed to Petroleum Ether Extracts of Annona Muricata

KEY: Positive Control= Ciprofloxacin $(5 \mathrm{mg} / \mathrm{Ml}$ 


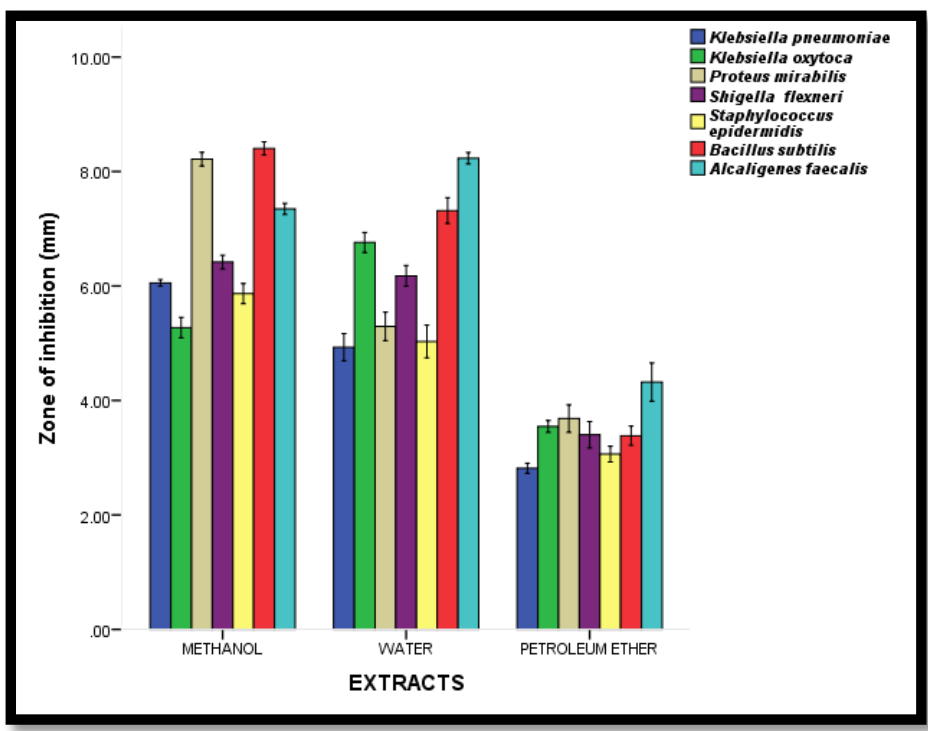

Figure 1: Sensitivity Patterns of Bacterial Isolates against Ocimum Gratissimum Extracts

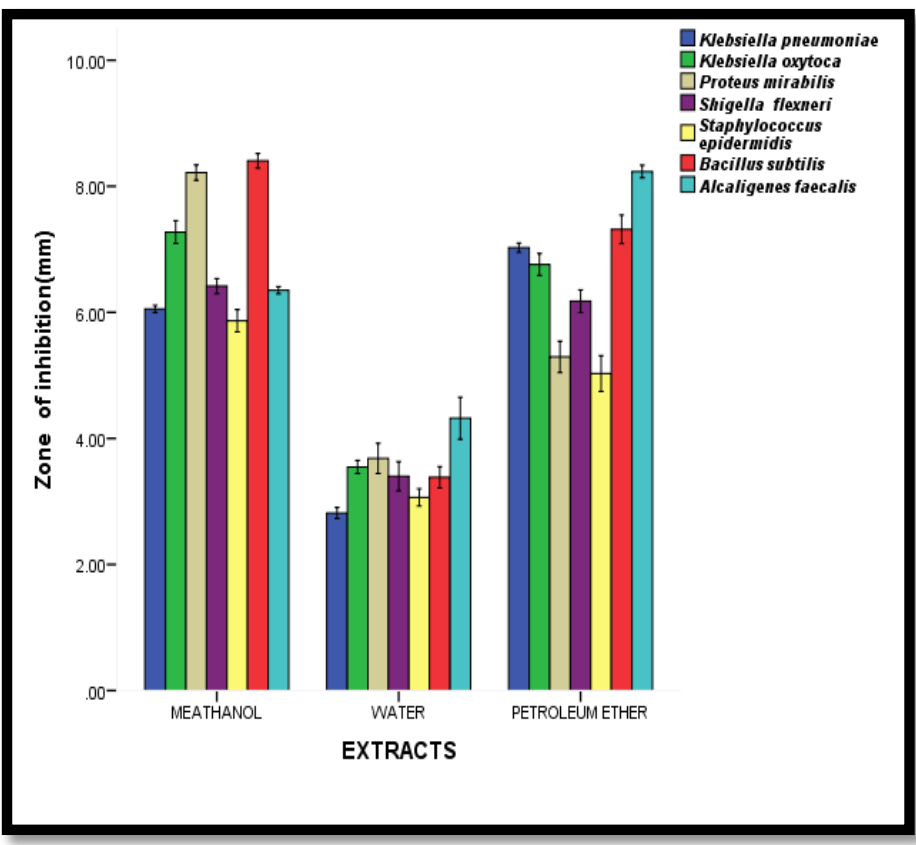

Figure 2: Sensitivity Patterns of Bacterial Isolates against Annona Muricata Extracts

\begin{tabular}{|c|c|c|c|c|}
\hline S/N & $\begin{array}{c}\text { Cultural and } \\
\text { Biochemical } \\
\text { Identities }\end{array}$ & $\begin{array}{c}\text { 16s rRNA Sequence } \\
\text { Identification }\end{array}$ & $\begin{array}{c}\text { Max } \\
\text { Identity }\end{array}$ & Accession Number \\
\hline 1 & Proteus mirabilis & $\begin{array}{c}\text { Proteus mirabilis strain } \\
\text { HI4320 }\end{array}$ & $97 \%$ & NC010554.1 \\
\hline 2 & Salmonella typhi & $\begin{array}{c}\text { Salmonella enterica } \\
\text { subsp.enterica serovar } \\
\text { Typhi str. CT18 }\end{array}$ & $100 \%$ & NC003198.1 \\
\hline 3 & $\begin{array}{c}\text { Pseudomonas } \\
\text { aeruginosa }\end{array}$ & $\begin{array}{c}\text { Pseudomonas fluorescens } \\
\text { SBW25 }\end{array}$ & $92 \%$ & NC012660.1 \\
\hline 4 & $\begin{array}{c}\text { Staphylococcus aureus } \\
\text { Staphylococcus cohnii } \\
\text { subsp. cohnii strain } \\
\text { 532 Contig16 }\end{array}$ & $99 \%$ & NZLATV01000012.1 \\
\hline 5 & Salmonella enterica & $\begin{array}{c}\text { Salmonella enterica subsp. } \\
\text { enterica serovar } \\
\text { Infantis }\end{array}$ & $80 \%$ & NZ LN649235.1 \\
\hline 6 & Escherichia coli & $\begin{array}{c}\text { Escherichia coli str. K12 } \\
\text { substr. DH10B }\end{array}$ & $100 \%$ & NC010473.1 \\
\hline 7 & Shigella flexneri & $\begin{array}{c}\text { Shigella flexneri 2a str. } \\
\text { 2457T }\end{array}$ & $100 \%$ & NC004741.1 \\
\hline
\end{tabular}




\begin{tabular}{|c|c|c|c|c|}
\hline S/N & $\begin{array}{c}\text { Cultural and } \\
\text { biochemical } \\
\text { identities }\end{array}$ & $\begin{array}{c}\text { 16s rRNA sequence } \\
\text { identification }\end{array}$ & $\begin{array}{c}\text { Max } \\
\text { Identity }\end{array}$ & Accession number \\
\hline 8 & Klebsiella pneumoniae & $\begin{array}{c}\text { Klebsiella pneumoniae } \\
\text { strain J1 }\end{array}$ & $99 \%$ & NZ CP013711.1 \\
\hline 9 & Citrobacter freundii & $\begin{array}{c}\text { Citrobacterfreundii partial } \\
\text { strain R4-2 }\end{array}$ & $95 \%$ & LN854584.1 \\
\hline 10 & Bacillus subtilis & $\begin{array}{c}\text { Bacillus subtilis strain DBS- } \\
\text { LAZ-03/17 }\end{array}$ & $90 \%$ & KY652120.1 \\
\hline 11 & Bacillus thuringensis & $\begin{array}{c}\text { Bacillus thuringiensis } \\
\text { strain AN11 }\end{array}$ & $92 \%$ & KC762741.1 \\
\hline 12 & Alcaligenes faecalis & $\begin{array}{c}\text { Alcaligenes faecalis strain } \\
\text { UG2-MRL }\end{array}$ & $83 \%$ & \\
\hline
\end{tabular}

Table 8: Molecular Identity of Bacterial Isolates from Food Handlers in Akure

\begin{tabular}{|c|c|c|c|}
\hline \multirow{2}{*}{ Phytochemicals } & Methanol & Water & Petroleum ether \\
\cline { 2 - 4 } & Extract & Extract & Extract \\
\hline Monosaccharides & + & + & - \\
\hline Pentoses & + & + & - \\
\hline Alkaloids & + & + & - \\
\hline Steroids & + & ++ & + \\
\hline Tannins & ++ & + & + \\
\hline Ketoses & + & + & + \\
\hline Arginine & + & + & + \\
\hline Cysteine & + & + & + \\
\hline Phenolic amino acids & + & + & - \\
\hline Anthraquinones & - & - & + \\
\hline Nitrogen and Halides (Cl- $)$ & + & + & + \\
\hline Sulphur and Sulphate ion & + & + & + \\
\hline Aromatic amino acid & + & + & + \\
\hline Flavonoids & + & + & + \\
\hline Saponins & ++ & + & + \\
\hline Terpenoids & + & - & + \\
\hline Phlobatannins & + & - & + \\
\hline Glycoside & + & - & + \\
\hline Cardiac compounds & + & + & + \\
\hline
\end{tabular}

Table 9: Qualitative Phytochemical Properties of Ocimum Gratissimum and Annona Muricata Leaves

\begin{tabular}{|c|c|c|c|c|c|c|}
\hline \multirow{3}{*}{ Phytochemicals } & \multicolumn{3}{|c|}{ Ocimum gratissimum } & \multicolumn{3}{|c|}{ Annona muricata } \\
\hline & Methanol & Water & $\begin{array}{c}\text { Petroleum } \\
\text { ether }\end{array}$ & Methanol & Water & $\begin{array}{c}\text { Petroleum } \\
\text { Ether }\end{array}$ \\
\hline & Extract & Extract & Extract & Extract & Extract & Extract \\
\hline Arginine & $4.75 \pm 0.27 \mathrm{c}$ & $3.81 \pm 0.00^{\mathrm{a}}$ & $1.24 \pm 0.06^{\mathrm{a}}$ & ND & ND & ND \\
\hline Steroids & $2.73 \pm 0.14^{\mathrm{a}}$ & $3.33 \pm 0.07 \mathrm{~b}$ & 0 & ND & ND & ND \\
\hline Sulphate ions & $2.85 \pm 0.28^{b}$ & $2.42 \pm 0.12^{\mathrm{c}}$ & 0 & ND & ND & ND \\
\hline Alkaloids & $3.99 \pm 0.32^{\mathrm{b}}$ & $4.16 \pm 0.19 \mathrm{a}$ & 0 & $3.89 \pm 0.82^{b}$ & $0.78 \pm 0.33^{c}$ & $4.56 \pm 0.49 \mathrm{~b}$ \\
\hline Amino acids & $2.97 \pm 0.16^{b}$ & $1.38 \pm 0.02^{\mathrm{a}}$ & $1.43 \pm 0.35^{b}$ & ND & ND & ND \\
\hline Tannins & $4.42 \pm 0.27 \mathrm{a}$ & $2.03 \pm 0.34 \mathrm{~b}$ & $1.00 \pm 0.21^{\mathrm{a}}$ & $4.44 \pm 0.27 c$ & $2.40 \pm 0.17 \mathrm{~b}$ & $3.43 \pm 0.09 \mathrm{~b}$ \\
\hline Saponins & $4.02 \pm 0.08^{a}$ & $3.45 \pm 0.26^{\mathrm{a}}$ & $1.01 \pm 0.36^{\mathrm{a}}$ & $3.03 \pm 0.24 \mathrm{~b}$ & 0 & 0 \\
\hline Flavonoids & $3.67 \pm 0.11^{c}$ & $3.00 \pm 0.12^{b}$ & $1.26 \pm 0.22^{\mathrm{c}}$ & $1.05 \pm 0.29 \mathrm{~b}$ & 0 & $1.89 \pm 0.16^{\mathrm{c}}$ \\
\hline Polyphenol & $1.02 \pm 0.32^{b}$ & ND & ND & $1.97 \pm 0.14^{b}$ & $0.26 \pm 0.07 a$ & $1.43 \pm 0.35^{b}$ \\
\hline
\end{tabular}

Table 10: Quantitative Phytochemical Properties of Ocimum Gratissimum and Annona Muricata Leaves

\section{Conclusion and Recommendations}

It can be deduced from this study that food handlers play a major role in the transfer of bacterial contaminants to the edible food that we purchase in our daily activities, although some of these foods may naturally habour these pathogens. Most of the bacteria present were susceptible to commercial antibiotics and extracts from selected medicinal plants. In addition, this research was developed to determine the most rampant bacterial pathogen that human can encounter when contaminated food is ingested. Staphylococcus aureus happens to be the most prominent bacteria found on the hands of food handlers and can cause notable food borne infections if not taken care of. Other bacteria like Bacillus spp, Citrobacter freundii, Escherichia coli, Klebsiella spp, Salmonella spp, Pseudomonas spp, should be taken cognisant of as they were isolated from the food handlers in the study. The use of PCR for the identification of the isolated bacteria was 
found to be more effective and accurate compared to the normal conventional method. The results of antimicrobial activity of Annona muricata and Ocimum gratissimum indicate the antimicrobial potential of the leaf extract which may be a source of new bioactive compounds for drug development and also suggests that the test plants could be promising in the treatment of food borne diseases.

The availability and accessibility to plant makes the use of $A$. muricata and 0 . gratissimum a cost-effective alternative medicine to the commercial antibiotics to which most organisms are now developing resistance. Further purification of the extract and identification of the active component is necessary to enhance greater antimicrobial potency.

Every microorganism has a set of nucleotide arrays which appears in series of sequenced data and are specific to each organism, thus making the identification accurate.

\section{References}

i. Ashelford, K. E., Chuzhanova, N. A., Fry, J. C., Jones, A. J., and Weightman, A. J. (2015). 16S rRNA sequence records currently held in public repositories. Journal of Applied Environmental Microbiology,71:7724-7736.

ii. Asoso, 0. S., Akharaiyi, F. C., and Animba, L. S. (2016) Antibacterial activities of plantain (Musa paradisaica) peel and fruits. Scholar research library. Der Pharmamacia Lettre, 8(5):5-11.

iii. Cheesbrough, M. (2010).District Laboratory practice in Tropical Countries, 2ndedition, Cambridge University Press, United Kingdom, 143: 70-95.

iv. Cowan, B. J., and Steel, G. H. (2016). Facemasks and Hand Hygiene to Prevent Influenza Transmission in Households. Journal of Internal Medicine, 151(7): 437-446.

v. Fawole, M. O. and Oso, B. A. (2007). Laboratory Manual of Microbiology, Spectrum Books, 1(3): 25-30.

vi. Heikens, E., Fleer, A., Paauw, A., Florijn, A. and Fluitt, A. C. (2015). Comparison of genotypic and phenotypic methods for species-level identification of clinical isolates of coagulase-negative Staphylococci. Journal of Clinical Microbiology,43:2286-2290.

vii. Jarvis, W.R. (2017). Handwashing: the Semmelweis lesson forgotten? International Journal of Systematic and Evolutionary Microbiology, 61(344):1311-1312.

viii. Liu, S. K. P., Woo, K..T., Yip, A. M., Fung, G. K., Woo, K.M., Chan, T. I. and Yuen, K.Y. (2017). Usefulness of the micro sequence 500 16S rDNA bacterial identification of anaerobic gram-positive bacilli isolated from blood cultures. Journal of Clinical Pathology, 59:219-222.

ix. Olutiola, R. O., Okwu, D. and Omodamiro, O. D. (2011). Effects of hexane extract and phytochemical content of Xylopia acthiopica and Ocimum gratissimum on the uterus of Guinea pig. Bio-Research, 3: 40-44.

x. Weisblum, B., and Davies, K. (2015). Traditional medicine in the Central Plateau in Haiti. 2. Ethnopharmacologic inventory. Journal of Ethnopharmacology, 17(1): 13-30. 